\title{
INVESTIGATION ABOUT THE EXTENT OF MODIFICATION EFFECT ON MODIFYING THE SURFACE OF THREE-DIMENSIONAL SHAPED MATERIAL BY COLD PLASMA
}

\author{
YORI IZUMI, NORIYUKI MOTEGI, TAKEO OHTE, SUGIO OHTANI* and AKIRA KOJIMA \\ Gunma College of Technology, Toriba-cho, Maebashi-shi, Gunma 371 \\ *Tokai University, Nishino, Numazu-shi, Shizuoka 410-03
}

\begin{abstract}
We irradiated the reactive plasma to the carbon material having a three dimensional shape in order to examine about the extent of surface modification. In this case, it is problem what region is improved and whether the surface is modified uniformly. The box which has a small hole on upper side was used as a sample, which consists of the GC plate, a spacer and a upper plate. The characteristics on the inner surface of GC plate which was changed by plasma entering from its hole were investigated. The estimation of modification effect was carried out by contact angle to water at some points on its surface. When the sample was treated by plasma, the upper plate thickness $\mathrm{t}$, the hole diameter $2 \mathrm{r}$ and pressure during plasma treatment were varied.

As the thickness $t$ was larger, effect on modifying the inner surface of GC plate was smaller and there was larger difference in its effect between the center and edge of the plate. In case that hole diameter $2 \mathrm{r}$ was varied, modification effect was increased and became uniformly by widening a hole. Even if $2 \mathrm{r}$ was considerably small $(0.5 \mathrm{~mm})$ with $1 \mathrm{~mm}$ of thickness, the modification effect was fairly large, which the contact angle decreased from $90^{\circ}$ (untreated value) to $43^{\circ}$ at the center $(x=0 \mathrm{~mm})$ by plasma treatment. This is considered that the extent of modification effect depends on the quantity or condition of modification sources, which relate to the balance among the consumption, the movement and the generation of modification sources. And the interesting results was obtained that as the value of pressure was higher, all over the GC surface was more improved. It may be found that the inner part of the hole is not plasma but sheath region, and the modification source is radical in this case.
\end{abstract}

\section{Introduction}

Surface modification of various materials with cold plasmas has been used widely and applied to many industrial fields[1][2]. Also that has been used for the carbon material in order to change its 
surface characteristics, especially wettabillity control,and the mechanism of this surface modification has been already investigated[3]. The degradation of improvement effects with time after plasma treatment which makes difficult to use could decreased by heating it in plasma treatment $\left.{ }^{4}\right]$. By . controlling plasma, the damageless modification was able to be made[5]. The relation between plasma effect and surface structure was investigated[6][7]. With respect to application of plasma treatment to the material, study on the shear strength of composites using carbon fibers irradiated by oxygen and argon plasma was carried out ${ }^{[8]}$. The researches about the mechanical strength of carbon fiber reinforced cement using carbon fibers treated by cold plasmas were made[9]-[14].

It is required recently that a lot of materials or not only flat but various shaped materials are treated[15]. We can think them three-dimensional shaped materials. A large number of materials are put on the electrode in the treatment chamber to treat them as shown in (a) and (b) in Fig.1. The cubical ((c) in Fig.1) or various shaped materials, for example, the hollow substance ((d) in Fig.1), material like a powder ((e) in Fig.1) and a tubular ((f) in Fig.1), are treated by plasma passing through a narrow gap between the parts in its material. In these cases, it is problem that what area of the surface is improved and whether the surface is modified throughout the material uniformly. However, those problems have never been investigated in detail until now, because the material treated by plasma has had small quantity and the even shape, which were, for example, the semiconductor wafers.

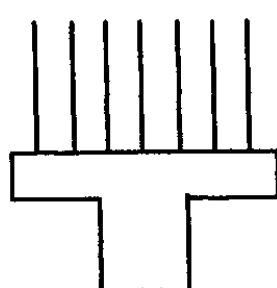

(a)

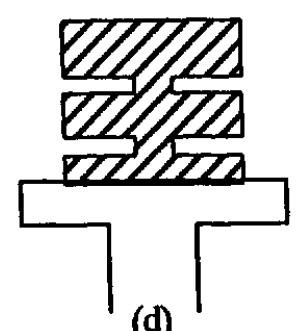

(d)

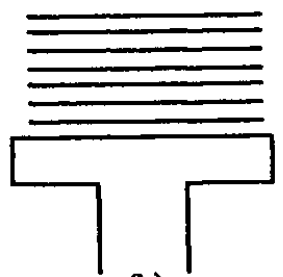

(b)

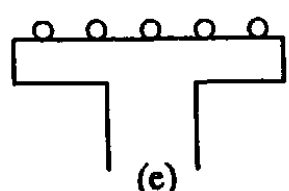

(e)

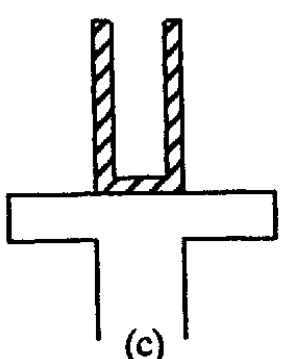

(c)

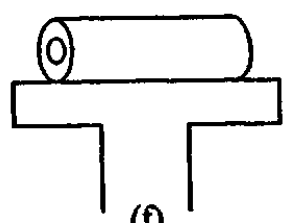

(f)

Fig.1 Plasma treatment of a large number of materials and various shaped materials. 
In this study, we examined about the extent of modification effects on the surface of a threedimensional shaped carbon material treated by plasma. This investigation makes it useful to use. The sample that is the simplified models of these shapes is used. We measured the surface characteristics of inner the sample which was changed by plasma with different conditions, and aimed to obtain the basic informations for solving these problems.

\section{Experimental}

\subsection{Specimen}

The specimen used in this experiment is shown in Fig.2. It is simplified three-dimensional shaped sample. This sample is like a box with a hole on upper side, and it consists of the carbon plate, a spacer and a upper plate.

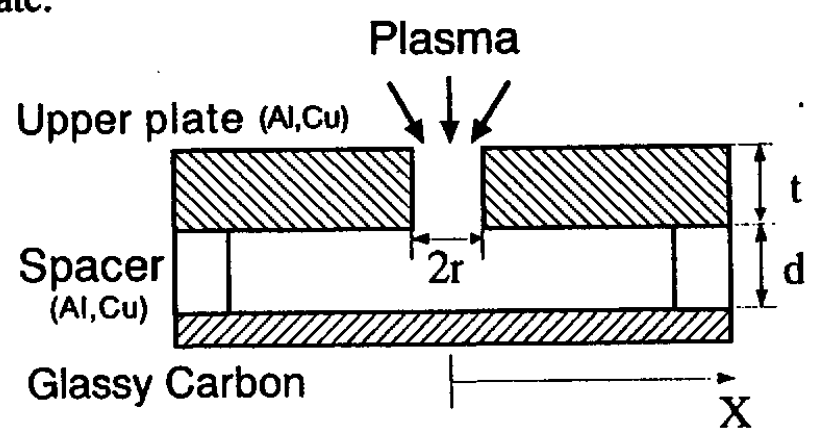

Fig.2 Sample used in this experiment.

The carbon plate used in this study is glassy carbon (GC, Showa denko, SG-2, longitudinal length: $25 \mathrm{~mm}$, transverse length:50 $\mathrm{mm}$, thickness: $0.6 \mathrm{~mm}$ ) plate. It is washed with acetone and water, and then dried before plasma treatment. At that time, the contact angle of water to GC surface is approximately $90^{\circ}$. The spacer and upper plate are made of aluminum or copper. The spacer is put between the GC plate and upper plate, The thickness $d$ of it, or the distance between these plates, is constant at $1.0 \mathrm{~mm}$. The upper plate has a hole of $2 \mathrm{r}$ in diameter and the modification sources, which modify the material, removes into the sample through this hole.The diameter $2 \mathrm{r}$ of a hole and plate the thickness $t$ of plate are changed.

The parts around the sample is furnished with a teflon tape in order to prevent the plasma entering from the part except its hole.

\subsection{Apparatus}

Fig. 3 shows the plasma apparatus used for this experiment. Treatments have been carried out in a 


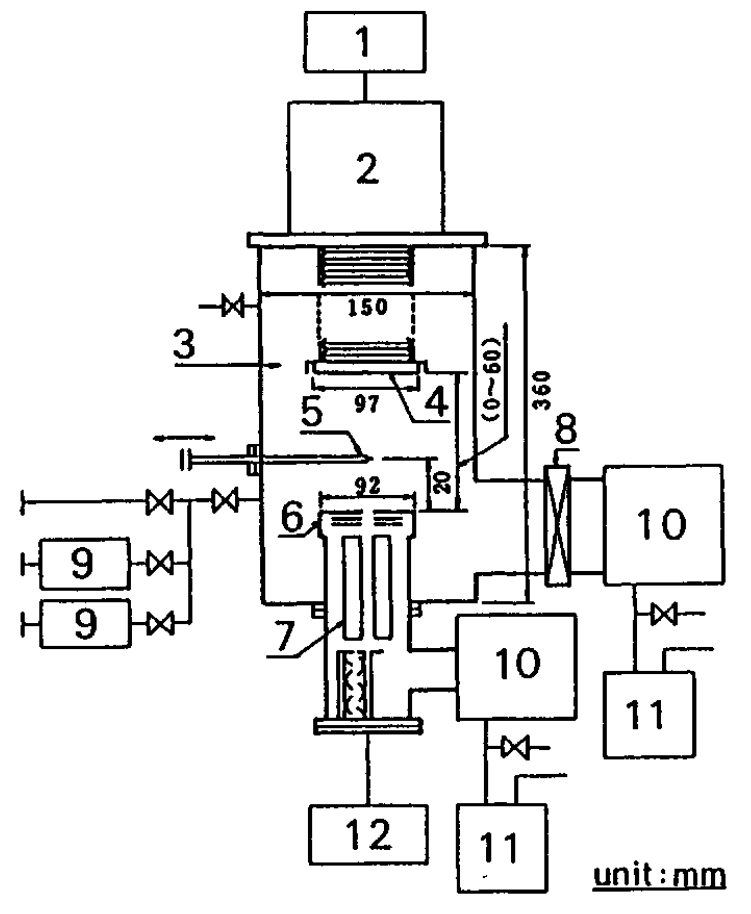

1: radio-frequency electric power source

2: impedance matching box

3: discharge chamber

4: power electrode

5: double prove

6: earth electrode

7: quadrupole mass spectrometer (Q.M.S.)

8: butterfly valve

9: mass flow controller

10: turbomolecular pump

11: rotary pump

12: radio-frequency unit for Q.M.S.

Fig.3 Plasma apparatus.

discharge chamber ( 3 in Fig.3) of inner diameter of $150 \mathrm{~mm}$ with two parallel-plate electrodes made of stainless steel. The earth electrode (6 in Fig. 3 ) is $92 \mathrm{~mm}$ in diameter, the power electrode (4 in Fig.3) is $97 \mathrm{~mm}$ in diameter and the distance between them is $40 \mathrm{~mm}$.

\subsection{Plasma treatment}

The sample which shapes like a box with a small hole is placed on the earth electrode and its hole is parallel to the electrodes. Then discharge chamber is evacuated to a high vacuum in advance by using the turbo molecular pump and the rotary pump. Oxygen gas is introduced to the discharge chamber through the mass flow controller (9 in Fig.3). Designated input power is supplied to the power electrode from the radio-frequency electric source (1 in Fig.3) through the impedance matching box ( 2 in Fig.3) and RF glow discharge plasma is generated between the electrodes. At this moment, pressure in this chamber is changed in various value. The treatment conditions are summarized in Table 1.

\subsection{Measurements}

After plasma treatment, the sample is separated, and the characteristics of the inner surface of GC plate is estimated by measuring the contact angle of water to GC surface. The measurements are 
Table 1 Treatment conditions.

\begin{tabular}{l|l}
\hline Pressure & $0.05 \sim 0.2$ Torr \\
\hline RF frequency & $13.56 \mathrm{MHz}$ \\
\hline RF power & $50 \mathrm{~W}$ \\
\hline Source gas & Oxygen \\
\hline Mass flow rate & $50 \mathrm{sccm}$ \\
\hline Power electrode diameter & $97 \mathrm{~mm}$ \\
\hline Earth electrode diameter & $92 \mathrm{~mm}$ \\
\hline Electrode spacing & $40 \mathrm{~mm}$ \\
\hline Plasma treatment time & $1 \mathrm{minute}$ \\
\hline Sample & Glassy carbon $(25 \times 50 \mathrm{~mm})$ \\
\hline Hole diameter & $0.5 \sim 5.0 \mathrm{~mm}$ \\
\hline Spacer or upper plate & Copper, Aluminum \\
\hline Spacer thickness & $1.0 \mathrm{~mm}$ \\
\hline Upper plate thickness & $0.5 \sim 10.0 \mathrm{~mm}$ \\
\hline
\end{tabular}

carried out at some positions on the line from the center $(x=0 \mathrm{~mm})$ to the edge $(x=25 \mathrm{~mm})$ on the inner surface of $\mathrm{GC}$ plate because of surveying the modified area and the degree of modification.

The contact angle of water to GC surface is measured in the air at room temperature by a goniometer-type contact angle meter (Erma, G-I). A drop of water (about $10 \mu \ell$ ) is put onto the GC surface and measurement is started after 1minute. Measuring the contact angle is carried out with time, and the elapsed change of surface characteristics of the treated GC plate by plasma is investigated.

\section{Results}

Before plasma treatment, the contact angle of water to GC surface was about $90^{\circ}$ and decreased by $\mathrm{O}_{2}$ plasma treatment.

Fig.4 shows the relation between the distance $\mathrm{x}$ from the center and the contact angle $\theta$ to water on GC surface treated by $O_{2}$ plasma. In this case, the diameter $2 \mathrm{r}$ of a hole was constant at $1.0 \mathrm{~mm}$ and the thickness $t$ of upper plate was varied. The contact angle was $62^{\circ}$ at the center $(x=0 \mathrm{~mm})$ and $91^{\circ}$ near the edge $(x=21 \mathrm{~mm})$ of the GC plate with $10 \mathrm{~mm}$ of thickness $\mathrm{t}(\mathrm{A}$ in Fig.4). At the part near the edge, GC surface was not modified. Difference between these values was big. But when 
the thickness $t$ was $0.5 \mathrm{~mm}$ ( $\mathrm{D}$ in Fig.4), the contact angle at the center and near the edge were $35^{\circ}$ and $40^{\circ}$ respectively. That means the modification effect is almost the same throughout the surface. The surface of GC plate has good uniformity.

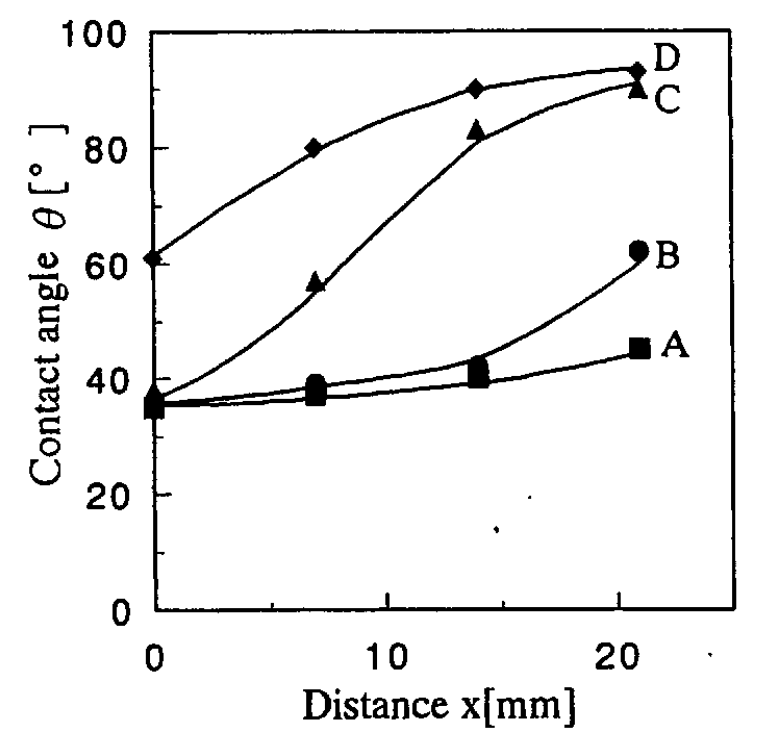

Fig.4 Relation between the distance $x$ and the contact angle $\theta$ treated by $\mathrm{O}_{2}$ plasma with various thickness $t$ of the upper plate.

(50W, 0.1Torr, $50 \mathrm{sccm}, 1 \mathrm{~min}$, thickness d:1mm, diameter $2 \mathrm{r}: 1 \mathrm{~mm}$ )
A: $\mathrm{t}=0.5 \mathrm{~mm}, \mathrm{~B}: \mathrm{t}=1 \mathrm{~mm}$, $\mathrm{C}: \mathrm{t}=5 \mathrm{~mm}$, D: $\mathrm{t}=10 \mathrm{~mm}$.

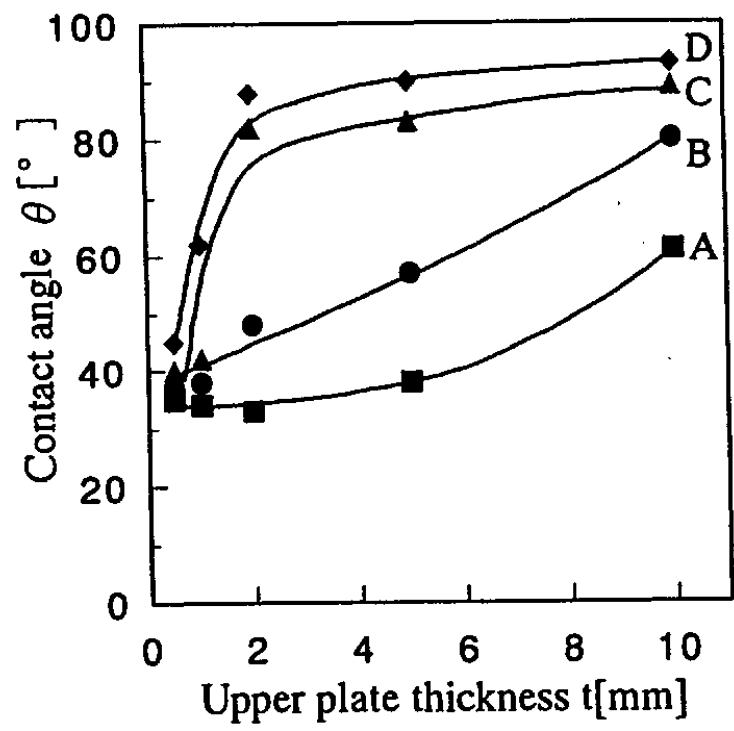

Fig.5 Relation between the thickness $\mathrm{t}$ and the contact angle $\theta$ treated by $\mathrm{O}_{2}$ plasma at several points on the surface.

(50W, 0.1Torr, 50sccm, $1 \mathrm{~min}$., thickness d:1mm, diameter $2 \mathrm{r}: 1 \mathrm{~mm}$ )
A: $\mathrm{x}=0 \mathrm{~mm}$,
B: $\mathrm{t}=7 \mathrm{~mm}$,
C: $x=14 \mathrm{~mm}$,
$D: t=21 \mathrm{~mm}$.

Fig.5 shows the relation between the thickness $t$ of upper plate and the contact angle $\theta$ to water treated by $\mathrm{O}_{2}$ plasma. In case that diameter $2 \mathrm{r}$ was constant at $1.0 \mathrm{~mm}$. The contact angle was $34^{\circ}$ $(\mathrm{t}=0.5 \mathrm{~mm})$ and $56^{\circ} \quad(\mathrm{t}=10 \mathrm{~mm})$ at the center $(\mathrm{x}=0 \mathrm{~mm}: \mathrm{A}$ in Fig. 5$)$ of $\mathrm{GC}$ plate. The degree of modification becomes smaller as the thickness $t$ is larger. At position near the edge $(x=21 \mathrm{~mm}: D$ in Fig.5), the contact angle was $45^{\circ} \quad(\mathrm{t}=0.5 \mathrm{~mm})$ and $90^{\circ} \quad(\mathrm{t}=10 \mathrm{~mm})$, there was large difference between their values. Especially when thickness $t$ was varied from $0.5 \mathrm{~mm}$ to $2 \mathrm{~mm}$, the change of contact angle was very large. There was almost nothing in difference of modification effect in case that thickness $\mathrm{t}$ was more than $2 \mathrm{~mm}$.

Fig.6 shows the relation between the distance $\mathrm{x}$ and the contact angle $\theta$ to water treated by $\mathrm{O}_{2}$ plasma. In this case, the thickness $t$ of upper plate was constant at $1 \mathrm{~mm}$ and diameter $2 \mathrm{r}$ of a hole 
was varied. The contact angle on GC surface was $43^{\circ} \quad(x=0 \mathrm{~mm})$ and $98^{\circ} \quad(x=21 \mathrm{~mm})$ with $0.5 \mathrm{~mm}$ of diameter $2 r$ (A in Fig.6). The area near the edge was not modified enough, there was large difference in modification effect between the center and edge of the surface. The contact angle were decreased at $7^{\circ} \quad(x=0 \mathrm{~mm})$ and $18^{\circ} \quad(x=21 \mathrm{~mm})$ by widening diameter $2 \mathrm{r}$ at $5 \mathrm{~mm}$ (C in Fig.6), and the GC surface was improved uniformly throughout the plate. In case that the diameter $2 \mathrm{r}$ was $1 \mathrm{~mm}$, it may be threshold value for uniform modification, the contact angle increased remarkably at the part where the distance $\mathrm{x}$ was more than $1.5 \mathrm{~mm}$.

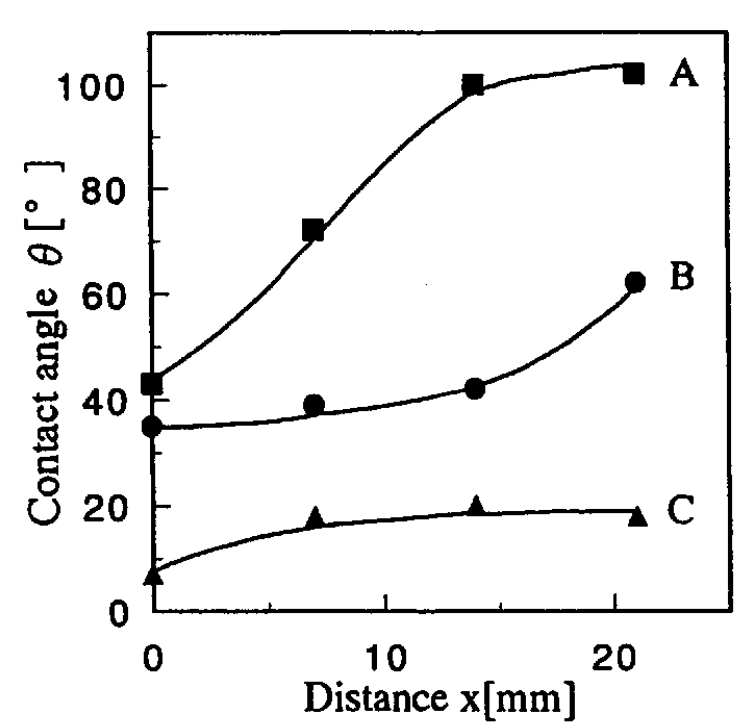

Fig. 6 Relation between the distance $x$ and the contact angle $\theta$ treated by $\mathrm{O}_{2}$ plasma with various diameter $2 \mathrm{r}$ of the hole.

(50W, 0.1Torr, $50 \mathrm{sccm}$, $1 \mathrm{~min}$., thickness d:1mm, thickness $\mathrm{t}: 1 \mathrm{~mm}$ ) A: $2 \mathrm{r}=0.5 \mathrm{~mm}, \mathrm{~B}: 2 \mathrm{r}=1 \mathrm{~mm}, \mathrm{C}: 2 \mathrm{r}=5 \mathrm{~mm}$.

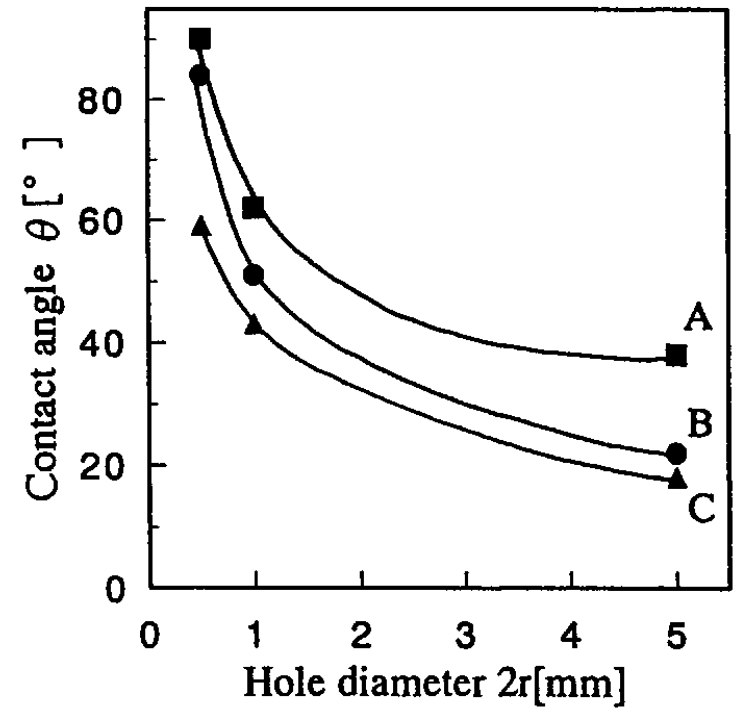

Fig. 7 Relation between the diameter $2 \mathrm{r}$ and the contact angle $\theta$ treated by $\mathrm{O}_{2}$ plasma with various thickness $t$ of the upper plate. (50W, 0.1Torr, $50 \mathrm{sccm}, 1 \mathrm{~min}$., thickness d:1mm, measurement point: $\mathrm{x}=0 \mathrm{~mm}$ )

$A: t=10 \mathrm{~mm}, B: t=5 \mathrm{~mm}, C: t=0.5 \mathrm{~mm}$.

Fig.7 shows the relation between the diameter $2 \mathrm{r}$ and the contact angle $\theta$ at the center $(x=0)$ of plate in case that the thickness $t$ is varied. When the thickness $t$ of the upper plate was $10 \mathrm{~mm}$ ( $\mathrm{A}$ in Fig.7), the contact angle was $90^{\circ}$ with $0.5 \mathrm{~mm}$ of a hole diameter $2 \mathrm{r}$ and the surface was scarcely modified although just under a hole. But with $5 \mathrm{~mm}$ of diameter $2 \mathrm{r}$, the contact angle was $40^{\circ}$ and modification effect became large. When the thickness $\mathrm{t}$ was $0.5 \mathrm{~mm}(\mathrm{C}$ in Fig.7), the contact angle was $59^{\circ}(2 \mathrm{r}=0.5 \mathrm{~mm})$ and $23^{\circ} \quad(2 \mathrm{r}=5 \mathrm{~mm})$. The modification effect was varied obviously by 
changing thickness $t$ and diameter $2 r$.

Fig. 8 shows the relation between the distance $\mathrm{x}$ and the contact angle $\theta$, in case that the pressure during plasma treatment is varied. When the pressure was 0.05Torr (A in Fig.8), the contact angle was $52^{\circ}$ at the center $(\mathrm{x}=0 \mathrm{~mm})$ and $78^{\circ}$ near the edge $(x=21 \mathrm{~mm})$ of GC surface. The modification effect on the surface was not so big, there was little effect near the edge. When the sample was treated at 0.2Torr (B in Fig.8), the contact angle at several points become smaller than that 0.2 Torr.

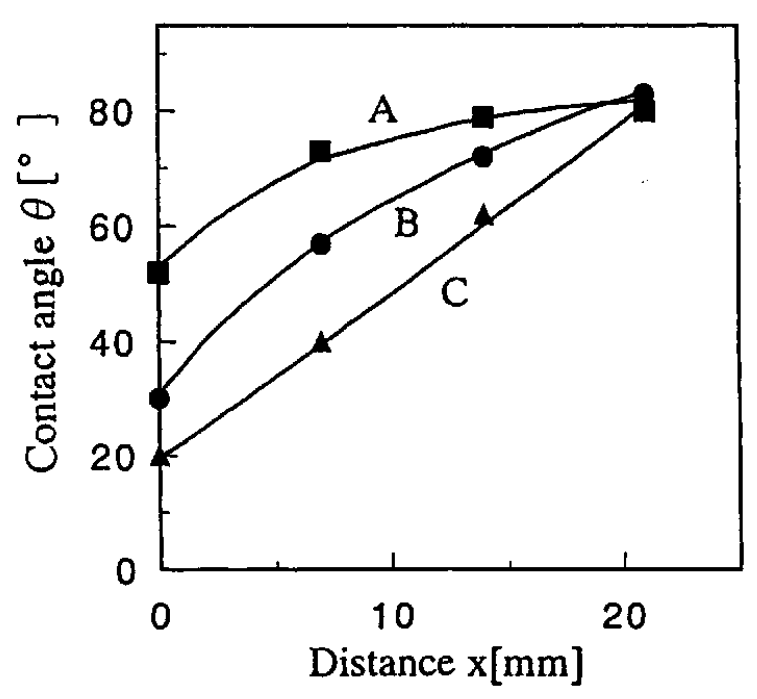

Fig.8 Relation between the distance $\mathrm{x}$ and the contact angle $\theta$ treated by $\mathrm{O}_{2}$ plasma with various presuure during the treatment.

(50W, 50sccm, 1min., thickness d:1mm, thickness t:0.5mm, diameter $2 \mathrm{r}: 0.5 \mathrm{~mm}$ ) A: 0.05Torr, B: 0.1Torr, C: 0.2Torr.



Fig.9 Relation between the pressure $p$ and the contact angle $\theta$ treated by $\mathrm{O}_{2}$ plasma at the center and near the edge of GC plate.

(50W, 50sccm, 1min., thickness d:1mm, thickness $\mathrm{t}: 0.5 \mathrm{~mm}$, diameter $2 \mathrm{r}: 0.5 \mathrm{~mm}$ ) A: $x=0 \mathrm{~mm}, \quad B: x=21 \mathrm{~mm}$.

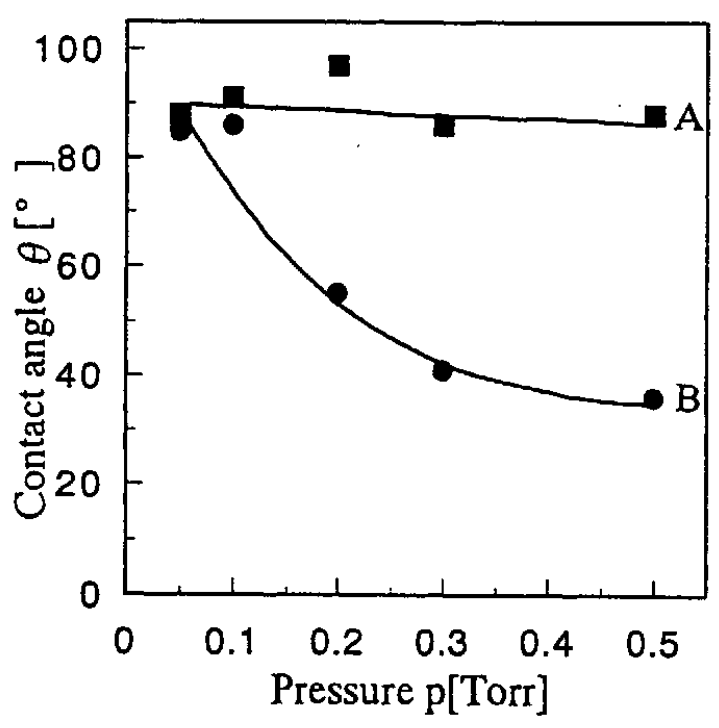

Fig.10 Relation between the pressure $p$ and the contact angle $\theta$ treated by $\mathrm{O}_{2}$ plasma at the center and near the edge of GC plate in case of using the different apparatus. (50W, 50sccm, 1min., thickness d:1mm, thickness $\mathrm{t}: 10 \mathrm{~mm}$, diameter $2 \mathrm{r}: 0.5 \mathrm{~mm}$ ) A: $x=0 \mathrm{~mm}, \quad B: x=21 \mathrm{~mm}$. 
Fig. 9 and Fig.10 show the relation between the pressure and the contact angle $\theta$ at two points $(x=0 \mathrm{~mm}$ and $x=21 \mathrm{~mm})$ treated by different apparatus. In case that the apparatus shown in Fig. 3 was used, the following results were obtained. When the pressure was less than 0.2Torr, the contact angle near the edge ( $x=21 \mathrm{~mm}$ :A in Fig.9) was constant at about $80^{\circ}$ and the degree of modification was very small. With 0.5 Torr of the pressure, the contact angle was $65^{\circ}$ and there was a little modification effect near the edge. But at the center ( $x=0 \mathrm{~mm}: B$ in Fig.9), the contact angle decreased with increasing the pressure and the degree of modification increased as the pressure increased from 0.05Torr to 0.5Torr. The result shown in Fig.10 obtained by using the different treatment apparatus indicated the similar to a tendency shown in Fig.9, it was confirmed that its result (tendency of the modification effect against the pressure) did not depend on the apparatus.

\section{Discussion}

The GC plate is improved by surface-modification sources, which contain the reactive ions, radicals, electrons and the light radiated from plasma. The extent of modification effect depends on kinds and the quantity of the modification sources entering into the sample through a hole. Their quantity has close relation to the thickness $t$, diameter $2 r$, spacer thickness $d$ and kinds of spacer and upper plate material with hole.

It has found that the modification sources could be passed even if the diameter $2 \mathrm{r}$ of its hole was considerable small. The modification effects of the sample surface was fairly large, which the contact angle decreased from $90^{\circ}$ (untreated value) to $43^{\circ}$ at the center $(x=0 \mathrm{~mm})$ by the plasma treatment, though the diameter $2 \mathrm{r}$ was considerably small $(0.5 \mathrm{~mm})$ with $1 \mathrm{~mm}$ of thickness $\mathrm{t}$. We think the mechanism of surface modification as follows. When the modification sources pass a hole into the sample, a part of them is consumed at this place, which means that the modification sources react to the atoms on the material surface and they are absorbed on its surface. A part of them adsorb at the inner surface wall of a hole and disappear after a while, so the modification sources which reach the GC surface become small. It is also considered that the adsorbed modification sources prevent themself which enter into the sample newly. As the thickness $t$ is larger, the modification sources adsorbed at inner surface of a hole become larger, and extent of the modification effect on the GC sample surface decreases. Whether the modification sources reach the sample surface or not is due to the following facts.

(1) How many sources can enter from the hole from plasma region. 
(2) How many sources are absorbed (consumed) at the part of wall of the hole.

(1) may be related with the condition around the entrance of hole, in which the edge effects occurs and the sheath is formed. (2) may be related with the surface area of the wall of a hole and the sheath condition of inner part of the hole.

The modification sources enter into the sample and remove to the edge and the spread of them occurs. They invade more into the sample as the hole is wider. The density of them becomes higher near the center of the GC plate, and they extend toward the edge of plate. Besides, the quantity which the modification sources introduce into the sample is large. Therefore, the extent of surface modification becomes large and all over the surface is modified uniformly as the diameter $2 \mathrm{r}$ of the hole is large.

And it has known that the modification effect of the surface becomes larger and uniformer as the spacer thickness $d$ is longer. In this case, the reason why the degree of modification increases may be considered that the discharge occurs and the modification sources are newly generated inner the sample.

The extent of the modification on inner surface was changed by position of the sample. It is considered that the difference of modification effect causes by the balance among the consumption (adsorption), the movement (spread) to the edge and the generation (discharge) of modification sources in the inner part of the sample. The condition of the modification on the sample surface depends on ones of the entrance part and inner part of a hole, and of inner region of the sample.

When the pressure is increased from 0.05 to 0.2 Torr, the modification effect must be reduced, because the plasma density, electron temperature and self-bias decrease. But in this experiment, modification effect increased. In order to confirm this pressure-dependency with respect to the modification effect, we carried out the same experiments by the different treatment apparatus. In this case, the modification effects increased when pressure increased. The same result was obtained. We think the reason why the whole of a hole is covered with not plasma but sheath. As the other reason, it is considered that the modification sources are the radical mainly in case of $\mathrm{O}_{2}$ plasma treatment, and also considered that the condition of inner part of the sample may not correspond to one of the plasma part. The detail phenomena which occurs in the sheath regions of the hole and the inner part of the sample has been investigated.

\section{Conclusion}

The sample which has a simplified three-dimensional shaped material was treated by $\mathrm{O}_{2}$ plasma in 
order to investigate the modified area and degree inner the surface. It was found that the modification effects were fairly large even if the diameter of the hole (the path) of the modification sources was considerably small $(2 \mathrm{r}=0.5 \mathrm{~mm})$.

As the thickness of upper plate in the sample is larger, the degree of surface modification becomes larger and only the area near the center of GC plate is modified. As the width of the hole is larger, the degree of surface modification becomes larger and the surface is modified uniformly throughout the GC plate. The extent of Surface-modification effect depends on the condition of the entrance and the inner wall of the hole and generation, movement and consumption of the modification sources in the sample box.

As the pressure during plasma treatment increases (from 0.05 to $0.2 \mathrm{Torr}$ ), the degree of modification becomes large. It may be considered that this is occurred because the diameter of the hole is small.

\section{References}

[1] Brian Chapman, Glow Discharge processes, John Wiley \& Sons,Inc., (1980) p177.

[2] M.Hudis, Techniques and Applications of Plasma Chemistry, edited by J.R.Hollahan,

A.T.Bell, John Willy \& Sons,Inc., (1974) p113.

[3] T.Ohte, S.Ohtani, A.Kojima and M.Katoh, Journal of The Vacuum Society of Japan, 36 (1993) 8.

[4] YORI IZUMI, MASAAKI KATOH, TAKEO OHTE, SUGIO OHTANI, AKIRA KOJIMA and NAOYA SAITOH, Journal of Photopolymer Science and Technology, 8 (1995) 431.

[5] Takeo Ohte, Sugio Ohtani, Akira Kojima and Masaaki Katoh, Trans.IEE of Japan, 114A (1994) 861.

[6] MASAAKI KATOH, YORI IZUMI, HIROSHI KIMURA, TAKEO OHTE, AKIRA KOJIMA and SUGIO OHTANI, Journal of Photopolymer Science and Technology, 8 (1995) 411.

[7] M.Katoh, Y.Izumi, T.Ohte, S.Ohtani, A.Kojima and H.Kimura, Journal of The Vacuum Society of Japan, 38 (1995) 663.

[8] M.NAKAHARA and Y.SANADA, Carbon, 33 (1995) 735.

[9] Akira Kojima, Sugio Ohtani, Teruo Thuthumi, Shigeru Furukawa and Takeo Ohte, TANSO [No.131], (1987) p161.

[10] Akira Kojima, Takeo Ohte, Sugio Ohtani, Michiya Ota, Hideya Kurihara and Eiji Ohtomo, TANSO [No.136], (1989) p2. 
[11] Akira Kojima, Sugio Ohtani, Koiti Nakamura, Shigeru Furukawa, Takeo Ohte and Hideya Kurihara, TANSO [No.136], (1989) p9.

[12] Akira Kojima, Sugio Ohtani, Norihiro Hayashi and Takeo Ohte, TANSO [No.140], (1989) p261.

[13] Takeo Ohte, Keisuke Shimizu, Akira Kojima, Shigeru Furukawa and Sugio Ohtani, TANSO [No.156], (1993) p2.

[14] Takeo Ohte, Keisuke Shimizu, Akira Kojima, Shigeru Furukawa and Sugio Ohtani, TANSO [No.158], (1993) p141.

[15] YORI IZUMI, MASAAKI KATOH, TAKEO OHTE, SUGIO OHTANI, AKIRA KOJIMA, TAKESHI TONEGI and JUNJI NEGISHI, Journal of Photopolymer Science and Technology, 8 (1995) 421. 